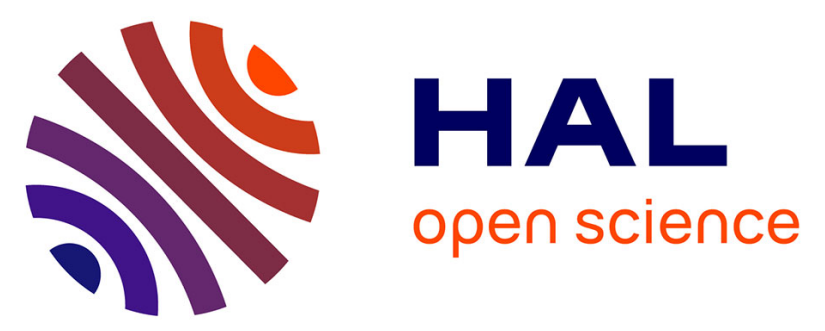

\title{
Hypermutator Salmonella Heidelberg induces an early cell death in epithelial cells
}

Sandrine Le Gall-David, Neila Zenbaa, Damien Bouchard, Marie-Thérèse

Lavault, Martine Bonnaure-Mallet, Anne Jolivet-Gougeon, Latifa Bousarghin

\section{- To cite this version:}

Sandrine Le Gall-David, Neila Zenbaa, Damien Bouchard, Marie-Thérèse Lavault, Martine BonnaureMallet, et al.. Hypermutator Salmonella Heidelberg induces an early cell death in epithelial cells. Veterinary Microbiology, 2015, 180 (1-2), pp.65-74. 10.1016/j.vetmic.2015.07.034 . hal-01187143

HAL Id: hal-01187143

https://hal-univ-rennes1.archives-ouvertes.fr/hal-01187143

Submitted on 1 Dec 2015

HAL is a multi-disciplinary open access archive for the deposit and dissemination of scientific research documents, whether they are published or not. The documents may come from teaching and research institutions in France or abroad, or from public or private research centers.
L'archive ouverte pluridisciplinaire HAL, est destinée au dépôt et à la diffusion de documents scientifiques de niveau recherche, publiés ou non, émanant des établissements d'enseignement et de recherche français ou étrangers, des laboratoires publics ou privés. 


\section{Hypermutator Salmonella Heidelberg induces an early cell death in epithelial cells}

Sandrine Le Gall-David ${ }^{\mathrm{a}}$, Neila Zenbaa ${ }^{\mathrm{a}}$, Damien Bouchard ${ }^{\mathrm{d}}$, Marie-Thérèse Lavault ${ }^{\mathrm{c}}$, Martine Bonnaure-Mallet $^{\mathrm{a}}$, Anne Jolivet-Gougeon ${ }^{\mathrm{a}, \mathrm{b}}$ and Latifa Bousarghin ${ }^{\mathrm{a}}{ }^{*}$

${ }^{a}$ Equipe Microbiologie Risques Infectieux, EA 1254, SFR Biosit, Université Européenne de Bretagne, Université de Rennes 1, 2 Avenue du Professeur Léon Bernard, 35043 Rennes, France.

${ }^{b}$ CHU, 2 rue Henri Le Guilloux, 35033 Rennes cedex 9, France

${ }^{c}$ Plateforme microscopie électronique MRic/ISFR Biosit/campus Santé, Rennes 1, France ${ }^{d}$ ANSES-ANMV, 8 rue Claude Bourgelat, 35306, Fougères, France.

Running title: Hypermutator Salmonella induce rapid cell death

*Correspondingauthor: L. BOUSARGHIN, Equipe Microbiologie Risques infectieux, EA 1254, Université de Rennes 1, 2 Avenue du Professeur Léon Bernard, 35043 RENNES, FRANCE.

Tel.: (33) 0223234898

Fax: (33) 0223234913

Email: Latifa.bousarghin@univ-rennes1.fr

\section{Highlights}

- "Hypermutator Salmonella Heidelberg induces an early cell death in epithelial cells" - We have investigated the virulence of a Salmonella with hypermutator phenotype.

- Epithelial cells were infected with hypermutator or normomutator strains. Internalised hypermutator strain induced epithelial cells death by apoptosis. $>$ MutS played a key role in this phenotype bacteria with an alteration in MutS. It provides useful information given that mutators are found in pathogenic specimens.

Abstract 
We have previously described that a strain of Salmonella Heidelberg with a hypermutator phenotype, B182, adhered strongly to HeLa cells. In this work, we showed that this hypermutator Salmonella strain invaded HeLa epithelial cells and induced cytoskeleton alteration. Those changes lead to HeLa cell death which was characteristic of apoptosis. For the first time, we showed that this hypermutator strain induced apoptosis associated with the activation of caspases 2, 9 and 3. Complementation of B182 strain showed a decrease in cells death induction. In the presence of other Salmonella Heidelberg with a normomutator phenotype, such as WT and SL486, cell death and caspase 3 were undetectable. These results suggested that early apoptosis and caspase 3 activation were specific to B182. Besides, B182 induced LDH release and caspase 3 activation in CaCo-2 and HCT116 cells. Heat-treated B182 and diffusible products failed to induce this phenotype. Epithelial cells treatment with cytochalasin D caused the inhibition of B182 internalisation and caspase 3 activation. These results showed that this cell death required active $S$. Heidelberg B182 protein synthesis and bacterial internalisation. However $\operatorname{sip} B$ and $\operatorname{sop} B$, usually involved in apoptosis induced by Salmonella were not overexpressed in B182, contrary to fimA and fliC. Comparative genome analysis showed numerous mutations as in $r p o S$ which would be more investigated. The role of the hypermutator phenotype might be suspected to be implicated in these specific features. This result expands our knowledge about strong mutators frequently found in bacterial organisms isolated from clinical specimens.

Key words: Salmonella Heidelberg, cell death, lactate dehydrogenase, apoptosis, caspase 2, caspase 3 .

\section{Introduction}

Salmonella Heidelberg is the third most common serovar causing invasive extraintestinal infections associated with severe disease symptoms (Wilmshurst and Sutcliffe, 
1995). Among natural population of $S$. Heidelberg, some strains display a hypermutator phenotype by harboring mutations in Methyl Mismatch Repair system (MMR) (Le Gall et al., 2009). Hypermutation allows some bacteria to adapt to adverse environmental conditions, including antibiotic exposure (Blázquez, 2003). The prevalence of strong mutators, which are characterized by an increased frequency of spontaneous mutations, ranges from about $1 \%$ among pathogenic strains of Escherichia coli to more than 30\% among Pseudomonas aeruginosa strains isolated from cystic fibrosis patients (Oliver et al., 2000). Identification of hypermutator strains among clinical bacteria has generated many questions of whether this evolution contributes to bacterial virulence (Mérino et al., 2002).

Intestinal epithelial cells are the primary host targets during the initial phase of enteroinvasive Salmonella infection (Ohl and Miller, 2001). Salmonella are able to replicate inside the intestinal cells and induce cell death (Kim et al., 1998;Paesold et al., 2002). Cell death commonly occurs through pyroptosis or apoptosis. Each of these cell death pathways is regulated by distinct molecular mechanisms. For instance, pyroptosis is an inflammatorymediated form of cell death characterized by activation of caspase 1, whereas apoptosis is a form of programmed cell death initiated by two major pathways, named the extrinsic and intrinsic pathways. In the case of apoptosis, coordinated activation of two groups of caspases is responsible for apoptotic cellular degradation. Based on their position in the apoptotic cascade, caspase 8 or caspase 9 initiates a downstream cascade of effector protease such as caspase 3, which cleaves various substrates and leads to the execution of cell death (Man et al., 2013). Salmonella trigger death of cultured epithelial cell lines in vitro by apoptosis, whereas in macrophages, Salmonella rapidly trigger pyroptosis which is dependent on caspase 1(Kim et al., 1998; Fink and Cookson, 2005).

Initial studies suggested that Type Three Secretion System (T3SS) was involved in cell death mechanism (Fink and Cookson, 2007). T3SS1 translocates SipA, SipB, SipC and 
SopB proteins, which are implicated in invasion through the plasma membrane of the host cell. SipB has been shown to induce macrophage apoptosis by activating caspase 1 , whereas SopB induces anti-apoptotic activity in infected epithelial cells (Hersh et al., 1999; Knodler et al., 2005).

The role of the strong mutator phenotype in pathogenic bacteria has already been discussed (Jolivet-Gougeon et al., 2011; Le Bars et al., 2014), but the link between this phenotype and virulence is not yet well understood. In the present work, the interaction between epithelial cells and $S$. Heidelberg with hypermutator phenotype was investigated. Indeed, S. Heidelberg B182 strain, used as a model in this study, was characterized by a mutation in mutS (Le Gall et al., 2009; Le Bars et al., 2012b). Internalised B182 bacteria induced rapid epithelial cell death by activating caspases 2, 9 and 3. This killing of epithelial cells required bacterial protein synthesis and direct interaction with living bacteria.

\section{Materials and methods}

\subsection{Bacterial strains, cell culture and infection protocol}

Strains of $S$. Heidelberg previously described (Le Gall et al., 2009) were used in this study: one was a B182, with a hypermutator phenotype (deletion of $12 \mathrm{bp}$ in $m u t S$ ), and the two others were normomutator wild type strains, WT and SL486 (Le Bars et al., 2014). B182 strain trans-complemented with the mutS wild-type gene from WT S. Heidelberg (Le Gall et al., 2009) was also used. Heat-killed bacteria were obtained by incubating B182 suspension at $65^{\circ} \mathrm{C}$ for $15 \mathrm{~min}$. Fresh bacteria were grown overnight at $37^{\circ} \mathrm{C}$ as previously described (Le Bars et al., 2012b).

The human epithelial cell line, HeLa, was grown in DMEM (Lonza, Verviers, Belgium). The HCT116 cell line, derived from human colon carcinoma, was grown in McCoy's 5A modified media (Life technologies, Invitrogen, Saint Aubin, France). CaCo-2 
cells, human epithelial colorectal adenocarcinoma cells, were maintained in culture in DMEM (Life technologies) containing 4,5g/L glucose. HeLa and HTC116 cells were supplemented with $10 \%$ fetal calf serum (FCS), $1 \%$ penicillin/streptomycin (Lonza) and 1\% L-Glutamine (Lonza) (Lonza). For CaCo-2 cells, cell culture media were supplemented with 20\% FCS, 1\% penicillin/streptomycin (Lonza) and 1\% L-Glutamine (Lonza). Cells were maintained in culture at $37{ }^{\circ} \mathrm{C}$ in a humidified atmosphere containing $5 \% \mathrm{CO}_{2}$.

One day before invasion assay, cells were trypsinized and seeded in 6-well or 24-well plates. Salmonella infections were conducted at a multiplicity of infection (MOI) of 100 bacteria per cell. Cells monolayers were incubated with Salmonella in DMEM at $37{ }^{\circ} \mathrm{C}$ in $5 \%$ $\mathrm{CO}_{2}$ for $30 \mathrm{~min}$. After incubation, non-adherent bacteria were removed by washing with Phosphate Buffer Saline (PBS, Lonza) and cells were incubated in DMEM containing gentamicin (Lonza) $(100 \mu \mathrm{g} / \mathrm{ml})$ in order to kill extracellular bacteria.

To inhibit bacterial internalisation, HeLa cells were treated with cytochalasin D (5 $\mu \mathrm{M}$, Sigma) $1 \mathrm{~h}$ prior to infection.

\subsection{Confocal imaging and transmission electron microscopy (TEM)}

For constitutive expression of GFP, B182 and WT strains were transformed with the modified plasmid pNF8 (pNF8 gfp-mut1). Immunofluorescence studies were performed on HeLa cells fixed in $1 \%$ paraformaldehyde (Sigma-Aldrich, L'lsle D'Abeau Chesnes, St. Quentin Fallavier, France). The actin cytoskeleton was labeled using TRITC-conjugated phalloidin (Sigma). CellLight Tubulin-RFP (Life Technologies) was used to visualize tubulin according to manufacturer's instructions. Signals were analyzed with a confocal microscope (TCS-SP5; Leica). Images were processed using ImageJ analysis software.

Following different times of infection (1, 2, 3, 6 and 24h), HeLa cells were also treated for transmission electron microscopy analysis as previously described (Le Bars et al., 2012b). 
Examination was performed with JEOL 1400 electron microscope operated at $120 \mathrm{kV}$ and pictures were obtained by Orius 1000 Gatan Camera.

\subsection{LDH release assay}

Lactate dehydrogenase (LDH) was released when cell lost its cell membrane integrity. After cells infection, the supernatant medium from infected cells was collected and the amount of LDH released was measured with a cytotoxicity detection kit (CytoTox 96 NonRadioactive Cytotoxicity Assay) from Promega (Charbonnières, France). LDH release was calculated as suggested by manufacturer's instructions.

\subsection{Measurement of apoptosis by flow cytometry analysis}

Discrimination between apoptotic and necrotic cells was performed by staining with annexinV-phycoerythrin (PE) and 7-aminoactinomycin (7'AAD) (BD Biosciences, Le Pont de Claix, France). Briefly, infected HeLa cells were harvested using trypsin and subsequent low-speed centrifugation $(3000 \times \mathrm{g}, 10 \mathrm{~min})$. Cell pellets were resuspended at $1 \times 10^{6} \mathrm{cells} / \mathrm{ml}$ in annexinV binding buffer and $100 \mu \mathrm{l}$ fractions were then incubated for 15 min with $5 \mu 1$ of AnnexinV-PE or/with $5 \mu 1$ with 7'AAD at room temperature in the dark. After the addition of $300 \mu \mathrm{l}$ from the binding buffer, the samples were analysed by flow cytometry using FCS 500 cytometer (Beckman Coulter, Gagny, France).

\subsection{Western blot analysis}

Equal amounts of infected cells were centrifuged and the pellet was resuspended in standard Laemmli buffer and boiled for $10 \mathrm{~min}$ to denature proteins. Proteins were separated by $12 \%$ SDS-polyacrylamide (Sigma) gel electrophoresis under denaturing conditions and transferred onto nitrocellulose membrane (Sigma). The membranes were blocked for $1 \mathrm{~h}$ in PBT (PBS with $0.05 \%$ Tween-20 (Sigma) containing 5\% milk). Immunoblots were probed with rabbit anti-caspases 2 or 3 polyclonal antibodies or with mouse anti-caspases 1,8 or 9 
polyclonal antibodies (Tebu-bio, Le Perray en Yvelines, France) for 1h. Detection of histone 3 with anti-histone 3 rabbit antibodies was also used as loading control. To detect antibodies reactions, the membranes were incubated for $1 \mathrm{~h}$ with alkaline phosphatase-conjugated antimouse IgG or anti-rabbit IgG antibodies (Sigma). Caspase proteins (pro- and active forms) were visualized using 5-bromo-4-chloro-3- indolyl-phosphate/NBT (Sigma) and the intensity of the bands was quantified using ImageJ software. The relative expression of cleaved caspases was corrected against histone 3 . The ratios between caspase 3 and histone 3 for each lane quantified were means for three independent experiments.

\subsection{Cell-contact cytotoxicity}

To determine if cell contact is required for B182 cytotoxicity, we used a transwell assay mounting membrane filter (Millipore, St Quentin en Yvelines, France) with tissue culture insert where HeLa cells were cultured in the lower chamber. B182 strain at MOI of 100 was added in the upper chamber. After incubation for $30 \mathrm{~min}$ at $37^{\circ} \mathrm{C}$, cells were washed and incubated in DMEM containing gentamicin $(100 \mu \mathrm{g} / \mathrm{ml})$ for $3 \mathrm{~h}$ in order to kill extracellular bacteria.

\section{7. $R N A$ extraction and real-time $R T-P C R$}

For RNA isolation, HeLa cells were infected with Salmonella strains for 10, 20 and 30 minutes, period in which effector proteins from T3SS1 were probably injected. Using three independent experiments, RNAs were isolated with the Qiagen RNeasy Midi/Maxi Kit (Qiagen, Courtaboeuf, France) and treated with DNase according to the manufacturer's instructions. cDNA samples and normalization of each gene to the 16S rRNA internal control were generated as previously described (Le Bars et al., 2012b). Forward (F) and reverse (R) primers were: $(\operatorname{sip} B \quad$ F): TCGCAGCGTCATAAACACTC and $(\operatorname{sip} B \quad \mathrm{R})$ : TGTtTCGCTGTCTCAACTGG; $(\operatorname{sip} C \quad \mathrm{~F})$ : AtGGAGCTTGCTGTCGTtTT and $(\operatorname{sip} C \mathrm{R})$ : 
GAGGTtGTGCAAACCCAGTT; (sopB F): TCATGATAGGGGGAAAGCAC and (sopB R): TGCAGCAGAGATGAAAATCG. The results, corresponding to relative expression values, were reported as the ratio of B182 to WT gene or B182 infected for 20 min to B182 infected for $10 \mathrm{~min}$.

\subsection{S. Heidelberg complete genome comparative analysis}

S. Heidelberg B182 chromosome (4,750,465 bp) (Le Bars et al., 2012a) was compared with 4 others Salmonella enterica subsp. enterica serovar Heidelberg chromosomes: str. CFSAN002064 (4,783,867 bp), str. CFSAN002069 (4,783,943 bp), str. 41578 (4,793,479 bp) and str. SL476 (4,888,768 bp). Genome sequences are available in GenBank under accession numbers: NC_017623.1 (B182), NZ_CP005995.1 (CFSAN002064), NC_021812 (CFSAN002069), NC_021810.1(41578) and NC_011083.1 (SL476). A Genomic comparison of the complete genome of these four related bacteria was performed using the progressive alignment option of the Mauve comparison software (Version 2.4.0) (Darling et al., 2004). Each sequence of identically colored blocks represented a collinear set of matching regions; a line is drawn to connect collinear blocks. As we had B182 and SL476 strains, we have compared their whole genomes and generated alignment data using Blastp, Blastn and Geneious R8 software (http://WWW.geneious.com). Some mutations were sequenced using Sanger technology (Applied Biosystem 3130 A, PerkinElmer, France). We used these primers: $(\operatorname{lrp} F)$ : TTTGAACAGTTTAATGCCGCC; $(\operatorname{lrp} R$ ): CATCACTACGTAAGTTCGGG), $(r p o S F)$ : AAAGATATTGATGACGCGCC; $(r p o S$ R): GTTATTTACCGCAGCGATAAAGC and the Big Dye Terminator Kit version 3.1 (Applied Biosystems, France). DNA sequence analysis was carried out using SeqScape software 2.5 (Applied Biosystems, Coignières, France). 


\subsection{Statistical analysis}

Statistical analyses included Student's bilateral test $(\mathrm{p}<0.05)$

\section{RESULTS}

\subsection{B182 infection induced cell death in epithelial cells}

In this study, we investigated the intracellular trafficking of B182, a strong mutator strain, in HeLa cells by using confocal microscopy (Fig.1A). This analysis showed that B182 adhered strongly to HeLa cells after $1 \mathrm{~h}$ of infection and were internalised after $3 \mathrm{~h}$. After $6 \mathrm{~h}$, actin labelling was reduced, suggesting that this Salmonella induced alterations to the cytoskeleton. Tubulin analysis also showed a decrease of labeling after $6 \mathrm{~h}$ of infection.

Transmission electron microscopy showed that B182 strain was adherent and intracellular bacteria after $1 \mathrm{~h}$ of infection (Fig.1B). At this time, the infected cells had a dense cytosol and a cytoplasmic membrane in its whole form as in the normal cells. However after $3 \mathrm{~h}$ of infection, all bacteria were internalised and morphological changes of HeLa cells were observed as cytoplasmic vacuolization. One interesting finding was that B182 infected cells at 6h displayed disrupted membrane integrity and cytosol leading to the release of B182 into the extracellular medium. After $24 \mathrm{~h}$ of infection, cell membrane was completely destroyed.

To quantify HeLa cells killing by B182, lactate dehydrogenase (LDH) was used for release assays (Fig. 2A). As shown in figure 2A, HeLa cells killing clearly increased in a time dependent manner, with a first killing noted after $3 \mathrm{~h}$ of infection. When B182 complemented strain (wild type $m u t S$ ) or another strain of $S$. Heidelberg with normomutator phenotype (WT) were used to infect HeLa cells, a lower release of LDH was observed. This result showed that this earlier cytotoxicity was characteristic to B182.

3.2. B182 infection induced apoptosis of HeLa cells by activating caspases 2, 9 and 3. 
Induction of apoptosis was first evaluated via the conventional annexinV-PE/7'AAD staining procedure (Fig. 2B). B182 strain induced 36, 43 and $70 \%$ of cell death after 1, 6 and $24 \mathrm{~h}$ of infection, respectively, confirming the results described above. After $1 \mathrm{~h}$ of infection, $25 \%$ of cells were in early apoptosis and $11 \%$ were in late apoptosis or in necrosis. After $6 \mathrm{~h}$ of infection, $39.5 \%$ of cells were in late apoptosis, whereas after $24 \mathrm{~h}, 48.6 \%$ of cells were in late apoptosis. After $24 \mathrm{~h}$ of infection, additional early apoptosis (27\%) was detected, representing probably an additional round of infection of new cells.

To determine if this apoptosis was specific to B182, WT was used (Fig. 2B). This WT strain showed a minimal effect, where the population in early apoptosis was next to the uninfected HeLa cells, confirming the results described in figure 2A. This apoptosis was specific to B182, while WT did not induce apoptosis in HeLa cells.

To uncover the spectrum of activated caspases, infected cells were harvested and probed with antibodies directed against caspases $1,2,3,8$ and 9 . As shown in figure $2 \mathrm{C}$, the processing of caspases 2, 3 and 9 was detected after analysis by western blot. Kinetics experiments revealed that caspases 2, 3 and 9 could be cleaved as early as $1 \mathrm{~h}$ after infection by B182. Caspase 8 as well as caspase 1 (data not shown) were not activated when HeLa cells were infected by B182 strain (Fig. 2C). Detection of histone 3, a loading control, was the same during the different times of infection. To evaluate the role of MutS in this phenotype, we have also investigated the activation of caspase 3 in the presence of the complemented strain B182. Only pro-caspase 3 was detected (Fig. 3A).

In order to determine if caspase 3 activation was specific to B182 infection, two other S. Heidelberg were tested: WT and SL486 with a normumotator phenotype (Le Gall et al., 2009; Le Bars et al., 2014). Figure 3B showed that SL486 did not activate caspase 3 whatever the time of infection was, whereas WT activated caspase 3 only after $24 \mathrm{~h}$ of infection. In 
addition, inoculation with other viable Salmonella WT and SL486 did not cause early apoptotic cell death (Fig. 3C).

In order to evaluate if B182 induced death of other epithelial cells, we have infected CaCo-2 and HCT116 cells. LDH was released earlier as for HeLa cells (Fig. 4A, C). Caspase 3 activation was also detected after $1 \mathrm{~h}$ of infection for the CaCo-2 cells and HCT116 cells (Fig. 4B), whereas the complemented strain B182 did not (Fig. 4D). The results indicated that B182 can kill the intestinal epithelial cells earlier.

\subsection{Caspase 3 activation by $B 182$ is cell contact- and invasion-dependent}

Physical separation of bacteria and HeLa cells using a transwell led to the loss of apoptosis induction. This result clearly indicated that a direct contact between bacteria and epithelial cells is needed for apoptosis (Fig. 5A). Heat-treated bacteria also failed to induce cell death, indicating that viable bacteria were required for this phenomenon to occur (Fig. 5A, B).The association of fluid factors secreted from B182 was also assessed by testing the supernatant from B182 culture on HeLa cells. Our results revealed that B182 supernatant did not induce caspase 3 activation (Fig. 5B). Results shown in figure 5C indicated that when cells were treated with cytochalasin D, caspase 3 was not cleaved, suggesting that bacterial internalisation was implicated in caspase 3 activation by B182 strain.

\subsection{T3SS1 effector genes, sipB and sopB, were not overexpressed in B182}

We have previously described that fimA and fliC were overexpressed in B182 (Le Bars et al., 2012b). In this study, we focused our attention on the Salmonella invasion genes sipB, $\operatorname{sip} C$ and $\operatorname{sop} B$ during the first times of infection, 10, 20 and 30 min. At first, we compared the expression of these genes between WT and B182. Figure 6A showed that these two strains expressed $\operatorname{sip} B$ and $\operatorname{sop} B$ genes at the same level. We also analysed $\operatorname{sip} B$ and $\operatorname{sop} B$ expression 
during different times of infection by B182. Before investigating these genes expression, we evaluated caspase 3 activation. As shown in figure 6B, activated caspase 3 was observed earlier, within $10 \mathrm{~min}$, after B182 infection and increased with time. The number of bacteria adherent to HeLa cells was also evaluated. Figure $6 \mathrm{C}$ showed that the number of B182 was the same between 10 and $20 \mathrm{~min}$, whereas after $30 \mathrm{~min}$ of infection, a significant difference could be observed. These results led us to compare the infection only after 10 and 20 min of infection. $\operatorname{sip} B$ and $\operatorname{sop} B$ expression did not increase with the infection time increase, suggesting that these effector proteins were not implicated in apoptosis induced by B182 (Fig. 6D).

\subsection{Comparative genome analysis of Salmonella Heidelberg strains B182}

As described above, $\operatorname{sip} B$ and $\operatorname{sop} B$ were not implicated in this B182 phenotype. Therefore, we used a comparative genome analysis with four other $S$. Heidelberg strains with a complete genome available on the NCBI data base. By using Mauve comparison software, we have shown that five collinear blocks (LCB) were found for the five strains (Fig.7). These blocks were rearranged in different ways in the genome of each strain. Deletions were visible in the SL476 strain and B182 strain did not contain major genomic rearrangements relative to the other strains. We therefore compared in detail the genetic differences between the different genomes. S. Heidelberg strains, B182 and SL476, genomes which were complete in the data base, contained notable differences. They were divided in 293 frameshifts (insertion and deletion) and 171 substitutions. $88 \%$ of the frameshifts were of small size (deletion or insertion of one nucleotide) and were located in the 28 pseudogenes of B182. Among substitutions, we had $59 \%$ of transitions and $28 \%$ of transversions. Substitutions were found in 5 pseudogenes of B182. Among the numerous mutations, we found in fimZ (insertion of $\mathrm{G}$ between two Ts in positions $36 \mathrm{bp}$ and $37 \mathrm{bp}$ ) and fliC (insertion of thymidine in position 
$1140 \mathrm{bp})$, these mutations were not confirmed by Sanger method. The major mutations confirmed by Sanger method showed a substitution of adenine by guanine in position $184 \mathrm{bp}$ of $\operatorname{lrp}$ (Leucine response protein) which leaded to threonine replacement by alanine (Fig. 8). The analysis also showed a substitution of $\mathrm{C}$ by $\mathrm{T}$ in position $154 \mathrm{bp}$ in $r p o S$ gene generating stop codon (Fig. 8). Mutations in mutS, $\operatorname{lrp}$ and $r p o S$ were also found when B182 genome was compared to other $S$. Heidelberg's in NCBI data base (str. CFSAN002069, str. CFSAN002064 and str. 41578). Further detailed comparative genomics are ongoing to identify factors that might explain this earlier cells death and to improve understanding of infections due to Salmonella enterica subsp. enterica serotype Heidelberg.

\section{Discussion}

We have previously described a strain of $S$. Heidelberg with a hypermutator phenotype (B182), adhering strongly to HeLa cells contrary to a normomutator strain WT (Le Bars et al., 2012b). In the present work, we investigated the molecular effects of this high adhesion on epithelial cells. B182 strain was demonstrated to induce epithelial cells morphology changes with an alteration of cytoskeleton, a higher susceptibility to cell death induction and a significant release of LDH. This death was identified as an apoptotic event with the activation of caspases 2, 9 and 3 earlier in infection. The complementation of B182 with the wild type mutS inhibited this phenotype, suggesting that mutS played a key role. Besides, our results showed that B182 induced cell death in other epithelial cells as CaCo-2 and HCT116 cells, whereas complemented B182 strain did not.

This apoptosis activation was B182 specific in opposition to $S$. Heidelberg normomutators, WT or SL486, which were unable to activate caspase 3. S. Typhimurium strains SR11 also activated caspases 2, 8, 6 and 3 in macrophages (Jesenberger et al., 2000). These two studies revealed that caspases cascade may vary between Salmonella species or 
strains. S. Dublin induced epithelial cell death by apoptosis which was delayed until 12-18h after infection, and detectable activation of caspase 3 was not observed until $6 \mathrm{~h}$ after infection (Kim et al., 1998;Paesold et al., 2002). In our study, caspase 3 activation started to be detected 10 min after infection, suggesting that B182 induced rapid apoptosis in epithelial cells and used apoptosis as a virulence factor. These results are in accordance with those of other authors who already described rapid apoptosis, pyroptosis, induced by Salmonella in macrophage after caspase 1 activation (Miao et al., 2006; Fink and Cookson, 2007). In this work, a rapid apoptosis occurring in epithelial cells without caspase 1 activation was demonstrated. This apoptosis, induced by B182, was related to death induced by other Salmonella in epithelial cells, but it was the first description of joint action of caspases 2, 9 and 3 in Salmonella after 1h of infection.

Salmonella possess a variety of mechanisms to produce cytopathic effects in infected host cells. Salmonella induce apoptosis in intestinal epithelial cells by a process that involves invasion mediated by SPI-1, but that required the functions of SPI-2. SipB was necessary for Salmonella-induced macrophage apoptosis to occur, and interacted with the essential proapoptotic enzyme caspase 1 in a manner that activated this protease (Hersh et al., 1999). Rapid pyroptosis and delayed apoptosis in macrophages are mediated by the SPI-1 effector SipB (Knodler and Finlay, 2001; Fink and Cookson, 2007). Early apoptosis of epithelial cells, which may be detrimental, both for Salmonella and for the host, is prevented by the SPI-1 effector SopB/SigD (Knodler and Finlay, 2001).

We showed that viable B182 induced caspase 3 activation after internalisation in HeLa cells. Inhibiting actin polymerization by cytochalasin D abolished programmed cell death induced by B182, which supports that the entry process triggers a signal transduction in epithelial cells that induces programmed cell death. We also revealed that a direct contact between epithelial cells and bacteria was required to induce cell death by B182 as 
demonstrated by others studies ( $\mathrm{Li}$ and $\mathrm{He}, 2012$ ). Infection with heat-killed bacteria did not cause cell death, suggesting that the factor was actively produced only by viable bacteria (Häcker et al., 2002; Paesold et al., 2002).

Since B182 strain is an environmental hypermutator, we speculate that this strain has accumulated mutations to adapt to its environment and to facilitate a more rapid niche expansion by using apoptosis as a virulence factor. We think also that mutS played a major role in this phenotype of cell death by acting with other mutated proteins. In this study, we have compared $S$. Heidelberg B182 genome with $S$. Heidelberg SL476 and found numerous mutations in B182 which need to be further verified in subsequent work. All these mutations needed to be confirmed as the 454 pyrosequencing methodology, used for B182, differs from the traditional Sanger sequencing in that sequencing error rates are higher (Balzer et al., 2011). We have focused our analysis on two mutations: $\operatorname{lrp}$ (leucine response protein) which regulates fimbriae expression (McFarland et al., 2008) and rpoS which regulates Salmonella virulence (Fang et al., 1992). These mutations in these two genes were confirmed by Sanger method analysis: $r p o S$ showed a stop codon in position $154 \mathrm{bp}$ whereas in $\operatorname{lrp}$, threonine was replaced by alanine. Given that both mutS and $\operatorname{rpoS}$ (stress resistance) are involved in important cellular functions, a deep analysis would help to evaluate the impact of rpoS mutation on the cell death phenotype induced by B182. Besides, some studies have also suggested that the region between mutS and rpoS may serve as an indicator for different virulence potential (Kotewicz et al., 2002, Brzuszkiewicz et al., 2009, Ewers et al., 2014). In every study in which pathogenic or commensal E. coli isolates were studied, several sequence variants of rpoS were reported. Both ends of the mutS/rpoS region need to be considered and additional studies are required to determine the role of mutS/rpoS in the B182 phenotype.

Even if our results indicated that mutS played a key role in this cell death phenotype, we can't exclude the impact of other proteins. As B182 overexpressed some genes such as fimA and 
fliC genes (Le Bars et al., 2012b), sipB and $\operatorname{sop} B$ expression was evaluated. Our results indicated that these genes were not overexpressed and seemed not to be implicated in this apoptosis. This apoptosis might be due to other proteins expressed by B182. Indeed, B182 overexpress fliC (Le Bars et al., 2012b). Recently, it was demonstrated that the ectopic expression of the Salmonella flagellin protein FliC during the intracellular phase of infection triggered pyroptosis of infected cells in vivo (Miao et al., 2010).

We also demonstrated that this strain contained a specific plasmid with numerous hypothetical proteins (Le Bars et al., 2012a). A plasmid, isolated from $S$. Typhi and transferred to $S$. Typhimurium, induced macrophage apoptosis (Wu et al., 2010b). It was also showed that this apoptosis was associated to the activation of caspases 9 and $3(\mathrm{Wu}$ et al., 2010a). These authors also demonstrated that $\mathrm{pR}_{\mathrm{ST} 98}$ plasmid could promote caspase 3 dependent apoptosis and suggested that its complex sequences of unknown functions might be involved in this process (Wu et al., 2014).

Thus, further investigations on the molecular events surrounding B182, but also comparison with other hypermutator strains, will provide a better understanding of how this evolution contributes to affect bacterial virulence. A better knowledge of this strain would give information on the acquisition of adaptive mutations and their impact on disease progression. Salmonella, one of the most important pathogens causing severe foodborne disease, can be transferred to humans via animals along the food chain impacting health and productivity (Majowicz et al., 2010). Great attention should be paid to the virulence of Salmonella clinical mutators. The results could give a valuable contribution to the ongoing analysis on pathoadaptative alterations of mutator strains that affect disease severity.

\section{Acknowledgments}


This work was supported by the Conseil Régional de Bretagne, UFR of pharmacy of Rennes, Rennes Métropole and funding from FEDER. We thank Agnes Burel for her help in TEM images analysis, Hervé Le Bars, Melinda Macoch, Alexis Février, Jean-Maxime Devaux and Alaa Sweidan. Confocal microscopy work was performed on Biosit platform (Microscopy Rennes Imaging Center, Stéphanie Dutertre). We thank also the Salmonella Genetic Stock Center (University of Calgary, Canada) for the strain Salmonella Heidelberg SL486 gift.

\section{References}

Balzer, S., Malde, K., Jonassen, I., 2011. Systematic exploration of error sources in pyrosequencing flowgram data. Bioinforma. Oxf. Engl. 27, i304-309.

Blázquez, J., 2003. Hypermutation as a factor contributing to the acquisition of antimicrobial resistance. Clin. Infect. Dis. Off. Publ. Infect. Dis. Soc. Am. 37, 1201-1209.

Darling, A.C.E., Mau, B., Blattner, F.R., Perna, N.T., 2004. Mauve: multiple alignment of conserved genomic sequence with rearrangements. Genome Res. 14, 1394-1403.

Ewers, C., Dematheis, F., Singamaneni, H.D., Nandanwar, N., Fruth, A., Diehl, I., Semmler, T., Wieler, L.H., 2014. Correlation between the genomic o454-nlpD region polymorphisms, virulence gene equipment and phylogenetic group of extraintestinal Escherichia coli (ExPEC) enables pathotyping irrespective of host, disease and source of isolation. Gut Pathog. 6, 37.

Fang, F.C., Libby, S.J., Buchmeier, N.A., Loewen, P.C., Switala, J., Harwood, J., Guiney, D.G., 1992. The alternative sigma factor katF (rpoS) regulates Salmonella virulence. Proc. Natl. Acad. Sci. U. S. A. 89, 11978-11982.

Fink, S.L., Cookson, B.T., 2007. Pyroptosis and host cell death responses during Salmonella infection. Cell. Microbiol. 9, 2562-2570.

Fink, S.L., Cookson, B.T., 2005. Apoptosis, pyroptosis, and necrosis: mechanistic description of dead and dying eukaryotic cells. Infect. Immun. 73, 1907-1916.

Häcker, H., Fürmann, C., Wagner, H., Häcker, G., 2002. Caspase-9/-3 activation and apoptosis are induced in mouse macrophages upon ingestion and digestion of Escherichia coli bacteria. J. Immunol. Baltim. Md 1950 169, 3172-3179. 
Hersh, D., Monack, D.M., Smith, M.R., Ghori, N., Falkow, S., Zychlinsky, A., 1999. The Salmonella invasin SipB induces macrophage apoptosis by binding to caspase-1. Proc. Natl. Acad. Sci. U. S. A. 96, 2396-2401.

Jesenberger, V., Procyk, K.J., Yuan, J., Reipert, S., Baccarini, M., 2000. Salmonella-induced caspase-2 activation in macrophages: a novel mechanism in pathogen-mediated apoptosis. J. Exp. Med. 192, 1035-1046.

Jolivet-Gougeon, A., Kovacs, B., Le Gall-David, S., Le Bars, H., Bousarghin, L., BonnaureMallet, M., Lobel, B., Guillé, F., Soussy, C.-J., Tenke, P., 2011. Bacterial hypermutation: clinical implications. J. Med. Microbiol. 60, 563-573.

Kim, J.M., Eckmann, L., Savidge, T.C., Lowe, D.C., Witthöft, T., Kagnoff, M.F., 1998. Apoptosis of human intestinal epithelial cells after bacterial invasion. J. Clin. Invest. $102,1815-1823$.

Knodler, L.A., Finlay, B.B., 2001. Salmonella and apoptosis: to live or let die? Microbes Infect. Inst. Pasteur 3, 1321-1326.

Kotewicz, M.L., Li, B., Levy, D.D., LeClerc, J.E., Shifflet, A.W., Cebula, T.A., 2002. Evolution of multi-gene segments in the mutS-rpoS intergenic region of Salmonella enterica serovar Typhimurium LT2. Microbiol. Read. Engl. 148, 2531-2540.

Le Bars, H., Bonnaure-Mallet, M., Barloy-Hubler, F., Jolivet-Gougeon, A., Bousarghin, L., 2014. Strong mutator phenotype drives faster adaptation from growth on glucose to growth on acetate in Salmonella. Microbiol. Read. Engl.

Le Bars, H., Bousarghin, L., Bonnaure-Mallet, M., Jolivet-Gougeon, A., Barloy-Hubler, F., 2012a. Complete genome sequence of the strong mutator Salmonella enterica subsp. enterica serotype Heidelberg strain B182. J. Bacteriol. 194, 3537-3538.

Le Bars, H., Le Gall-David, S., Renoux, V.M., Bonnaure-Mallet, M., Jolivet-Gougeon, A., Bousarghin, L., 2012b. Impact of a mutator phenotype on motility and cell adherence in Salmonella Heidelberg. Vet. Microbiol. 159, 99-106.

Le Gall, S., Desbordes, L., Gracieux, P., Saffroy, S., Bousarghin, L., Bonnaure-Mallet, M., Jolivet-Gougeon, A., 2009. Distribution of mutation frequencies among Salmonella enterica isolates from animal and human sources and genetic characterization of a Salmonella Heidelberg hypermutator. Vet. Microbiol. 137, 306-312.

Li, X., He, Y., 2012. Caspase-2-dependent dendritic cell death, maturation, and priming of T cells in response to Brucella abortus infection. Plos One 7, e43512.

Majowicz, S.E., Musto, J., Scallan, E., Angulo, F.J., Kirk, M., O’Brien, S.J., Jones, T.F., Fazil, A., Hoekstra, R.M., International Collaboration on Enteric Disease "Burden of 
Illness" Studies, 2010. The global burden of nontyphoidal Salmonella gastroenteritis. Clin. Infect. Dis. Off. Publ. Infect. Dis. Soc. Am. 50, 882-889.

Man, S.M., Tourlomousis, P., Hopkins, L., Monie, T.P., Fitzgerald, K.A., Bryant, C.E., 2013. Salmonella infection induces recruitment of Caspase-8 to the inflammasome to modulate IL-1 $\beta$ production. J. Immunol. Baltim. Md 1950 191, 5239-5246.

McFarland, K.A., Lucchini, S., Hinton, J.C.D., Dorman, C.J., 2008. The leucine-responsive regulatory protein, Lrp, activates transcription of the fim operon in Salmonella enterica serovar Typhimurium via the fimZ regulatory gene. J. Bacteriol. 190, 602612.

Mérino, D., Réglier-Poupet, H., Berche, P., Charbit, A., European Listeria Genome Consortium, 2002. A hypermutator phenotype attenuates the virulence of Listeria monocytogenes in a mouse model. Mol. Microbiol. 44, 877-887.

Miao, E.A., Alpuche-Aranda, C.M., Dors, M., Clark, A.E., Bader, M.W., Miller, S.I., Aderem, A., 2006. Cytoplasmic flagellin activates caspase-1 and secretion of interleukin 1beta via Ipaf. Nat. Immunol. 7, 569-575.

Miao, E.A., Leaf, I.A., Treuting, P.M., Mao, D.P., Dors, M., Sarkar, A., Warren, S.E., Wewers, M.D., Aderem, A., 2010. Caspase-1-induced pyroptosis is an innate immune effector mechanism against intracellular bacteria. Nat. Immunol. 11, 1136-1142.

Ohl, M.E., Miller, S.I., 2001. Salmonella: a model for bacterial pathogenesis. Annu. Rev. Med. 52, 259-274.

Oliver, A., Cantón, R., Campo, P., Baquero, F., Blázquez, J., 2000. High frequency of hypermutable Pseudomonas aeruginosa in cystic fibrosis lung infection. Science 288, $1251-1254$.

Paesold, G., Guiney, D.G., Eckmann, L., Kagnoff, M.F., 2002. Genes in the Salmonella pathogenicity island 2 and the Salmonella virulence plasmid are essential for Salmonella-induced apoptosis in intestinal epithelial cells. Cell. Microbiol. 4, 771781.

Wilmshurst, P., Sutcliffe, H., 1995. Splenic abscess due to Salmonella Heidelberg. Clin. Infect. Dis. Off. Publ. Infect. Dis. Soc. Am. 21, 1065.

Wu, S., Chu, Y., Yang, Y., Li, Y., He, P., Zheng, Y., Zhang, C., Liu, Q., Han, L., Huang, R., 2014. Inhibition of macrophage autophagy induced by Salmonella enterica serovar typhi plasmid. Front. Biosci. Landmark Ed. 19, 490-503. 
Wu, S., Li, Y., Xu, Y., Li, Q., Chu, Y., Huang, R., Qin, Z., 2010a. A Salmonella enterica serovar Typhi plasmid induces rapid and massive apoptosis in infected macrophages. Cell. Mol. Immunol. 7, 271-278.

Wu, S., Li, Y., Xu, Y., Song, G., Qin, Z., Huang, R., 2010b. Macrophage apoptosis associated with Salmonella enterica serovar Typhi plasmid. Indian J. Exp. Biol. 48, 773-777.

Figures captions

Fig. 1. S. Heidelberg B182 disturbed cytoplasm organization. Confocal microscopy analysis (A): HeLa cells were infected with B182 expressing GFP. Infected cells were then fixed and labelled with TRITC-phalloidin for detection of filamentous actin or transfected with cellLight Tubulin-RFP to detect tubulin. (B) Transmission electron microscopy analysis revealed that B182 were internalised into HeLa cells after 1h and induced cell morphology changes which lead to cell death (3h, 6h and 24h) compared to uninfected cells (HeLa). Bars, $5 \mu \mathrm{M}$.

Fig. 2. S. Heidelberg B182 induced HeLa cells death. (A) B182 induced release of LDH. Cytotoxicity was determined by measuring the release of the cytoplasmic enzyme LDH into the culture supernatant after infection with $S$. Heidelberg B182, the complemented B182 or WT. Results represent the mean of 3 independent experiments. Significant difference $(\mathrm{p}<0.05)$ was compared to $1 \mathrm{~h}$ of infection. (B) $S$. Heidelberg B182 induced apoptosis in HeLa cells. HeLa cells were infected by B182 or WT strains stained with PE-labelled annexinV and 7'AAD and analysed by flow cytometry. This co-staining (AnnexinV/ 7'AAD) revealed different cell populations: living cells (annexinV negative/7'AAD negative), cells in early apoptosis (annexinV positive/7'AAD negative), cells in late apoptosis or in necrosis (annexin $\mathrm{V}$ positive/7'AAD positive). (C) Activation of caspases occurs in cells infected with B182. Time course of caspases 2, 3, 8 and 9 expressions in B182 infected HeLa cells analysed by western blot. Pro-caspases and caspases were detected by anti-caspase antibodies. Arrows 
indicate inactive pro-caspase and active caspase. Detection of histone 3 was a loading control. The numbers are the ratios between caspase 3 and histone 3 for each lane quantified with the ImageJ programme. The ratios between caspase 3 and histone 3 for each lane quantified are means for three independent experiments.

Fig. 3. Induction of epithelial cells death is specific to B182. (A) Detection of caspase 3 in HeLa cells infected with the complemented B182 strain (wild type mutS) or with others Salmonella Heidelberg strains SL486 (B) or WT (C) as revealed by western blot. The numbers are the ratios between caspase 3 and histone 3 for each lane quantified with the ImageJ programme.

Fig. 4. B182 induced also cell death in intestinal epithelial cells: CaCo-2 and HCT116. When CaCo-2 an HCT116 cells were infected with B182, LDH release (A) and caspase 3 activation (B) were observed whereas with the complemented B182 strain, they did not (C, D). The numbers are the ratios between caspase 3 and histone 3 for each lane quantified with the ImageJ programme. The ratios between caspase 3 and histone 3 for each lane quantified are means for three independent experiments. Significant difference $(*: p<0.05)$ was compared to 1h of infection.

Fig. 5. Characterization of B182 components leading to HeLa cell death.

(A) Contact between viable B182 and HeLa cells induced apoptosis. Flow cytometry analysis showed that heat-killed $\mathrm{B} 182\left(65^{\circ} \mathrm{C}\right)$ and $\mathrm{B} 182$ separated by transwell from HeLa cells (upper space) do not induce apoptosis. (B) Activation of caspase 3 occurs only in the presence of viable B182. Western blot analysis showed that filtrated B182 culture supernatant (2) and heat- killed B182 (3) prevented caspase 3 activation induced by B182 (4) as in untreated cells 
(1). (C) Activation of caspase 3 occurs only in the presence of internalised B182. Infected HeLa cells treated with cytochalasin D (1) did not show caspase 3 activation as uninfected cells (2) contrary to untreated infected cells (3).

Fig. 6. $\operatorname{sip} B, \operatorname{sop} B$ and $\operatorname{sip} C$ expression during the first time (10, 20 and $30 \mathrm{~min})$ of contact between B182 and HeLa cells. (A) relative expression between WT and B182; (B) Caspase 3 activation after B182 infection; (C) Enumeration of B182 after its infection; D) relative expression between 10 and 20 min of infection with B182 (*: p<0.05).

Fig. 7. Genomic alignment of four Salmonella Heidelberg genomes and B182. Alignment statistics were generated and rendered by Mauve progressive alignment software. Each collinear block (LCB) had a color, each sequence of identically colored blocks represented a collinear set of matching regions, a line was drawn to connect collinear block.

Fig. 8. Nucleoside and amino acid sequences alignment of $r p o S$ and $\operatorname{lrp}$ from B182 to SL476 strains. Numbers indicate the sequence position of the residues in each alignment block; circles indicated mutations. The sequence alignment was produced using the mauve algorithm within the Geneious software package. 
A

HeLa /B182

HeLa
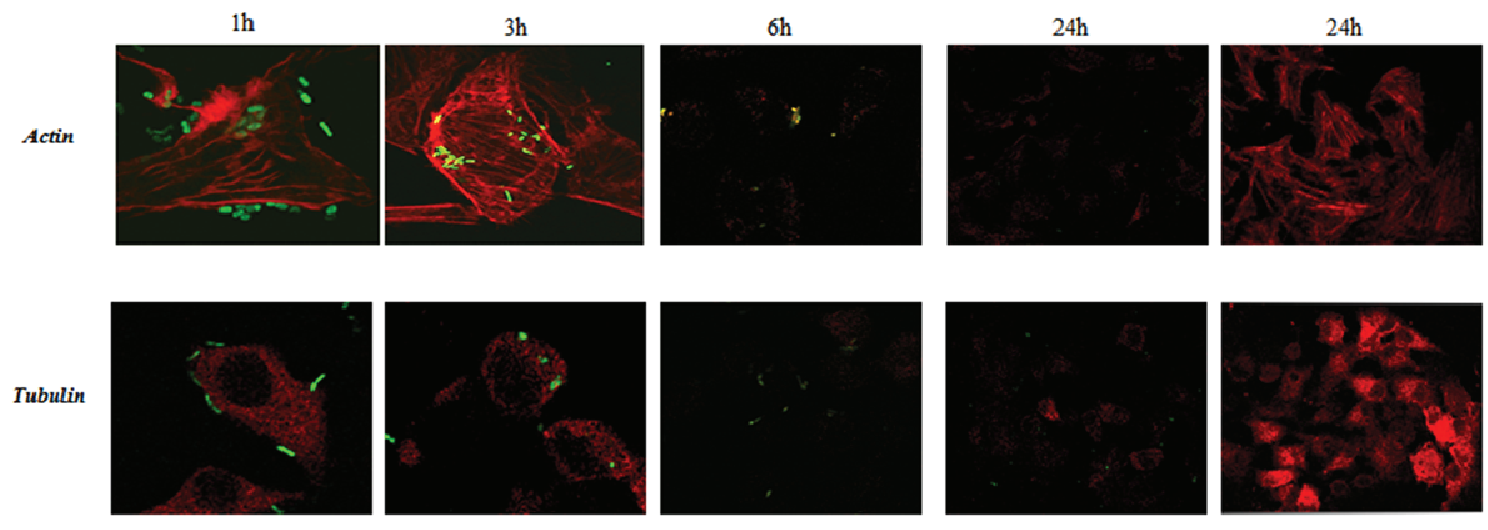

B
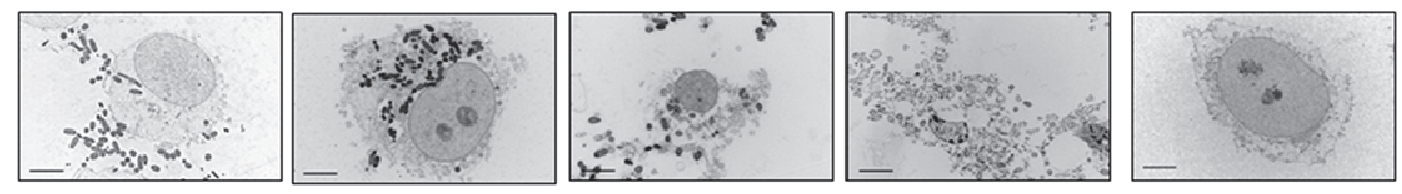

Fig. 1

figure 1Le Gall et al . 
A

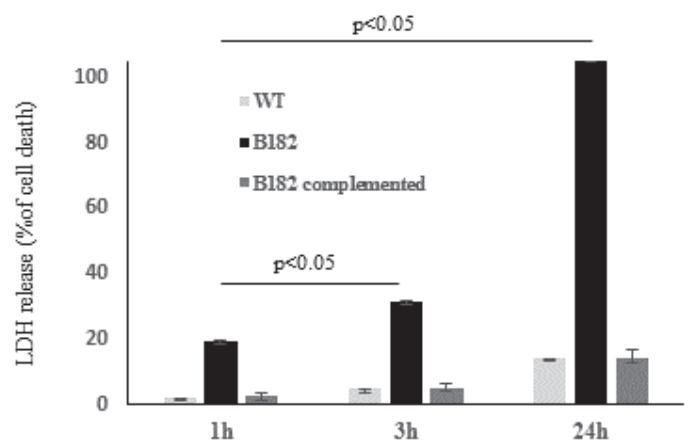

C

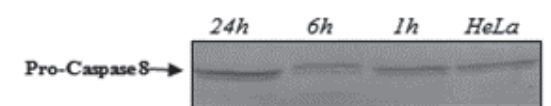

$\begin{array}{lllll}20.00 & 0.09 & 0.05 & 0.07 & 0.01\end{array}$
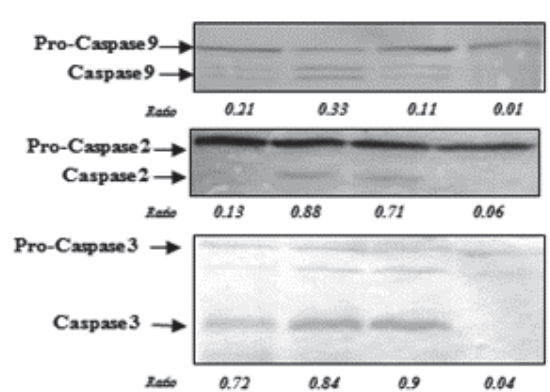

Fig. 2

figure 2 Le Gall et al .
B

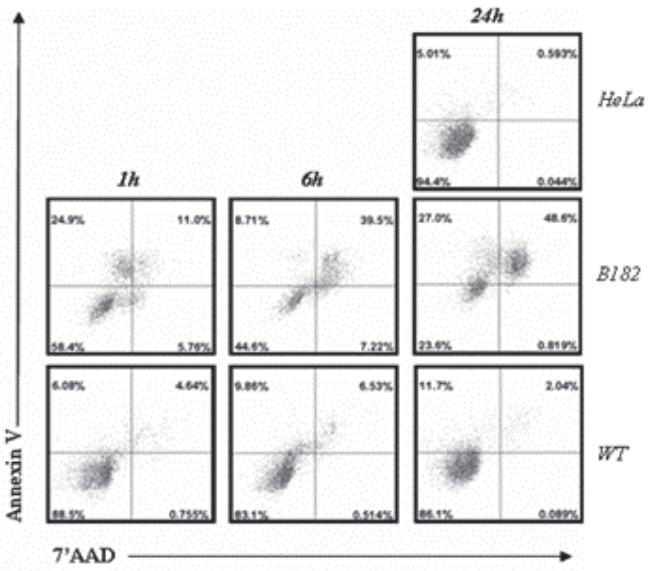


A

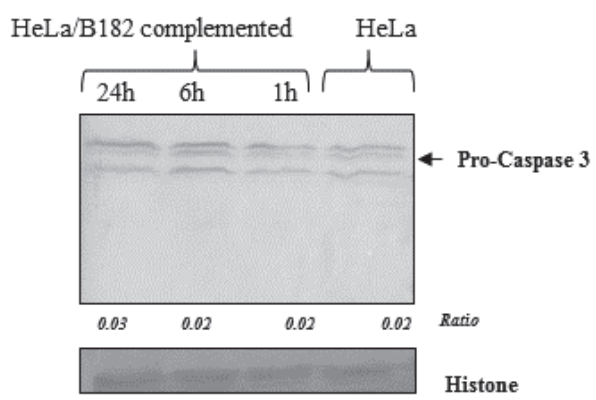

B

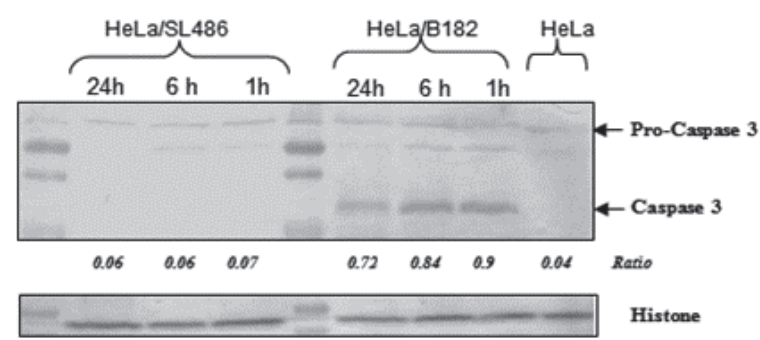

C

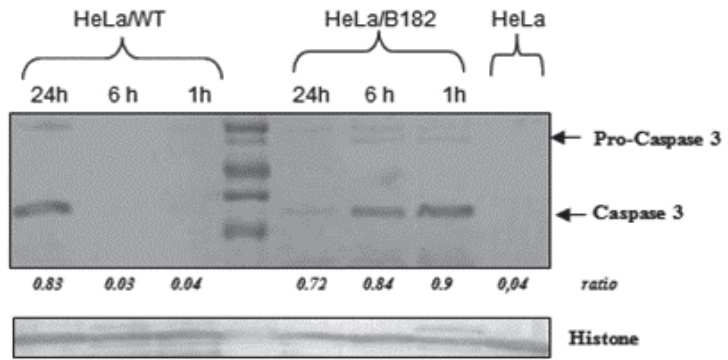

Fig. 3

figure 3 Le Gall et al . 


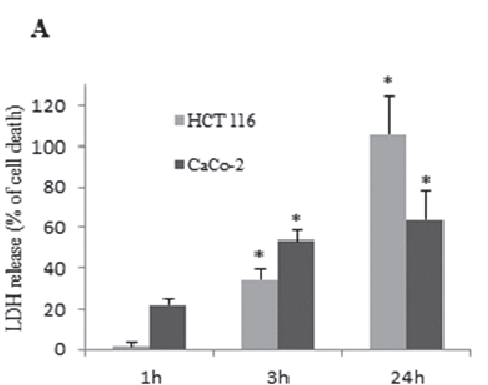

C

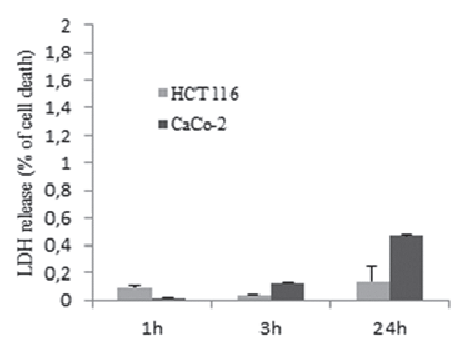

Fig. 4
B

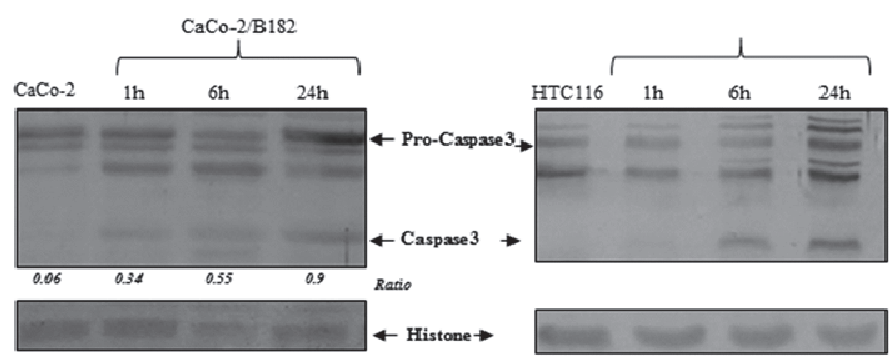

D

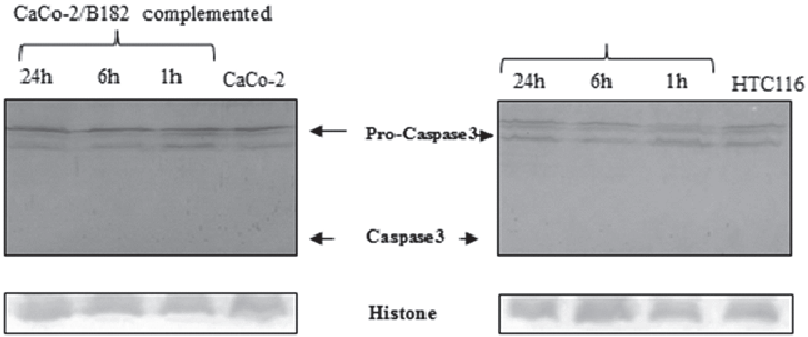

figure 4 Le Gall et al . 


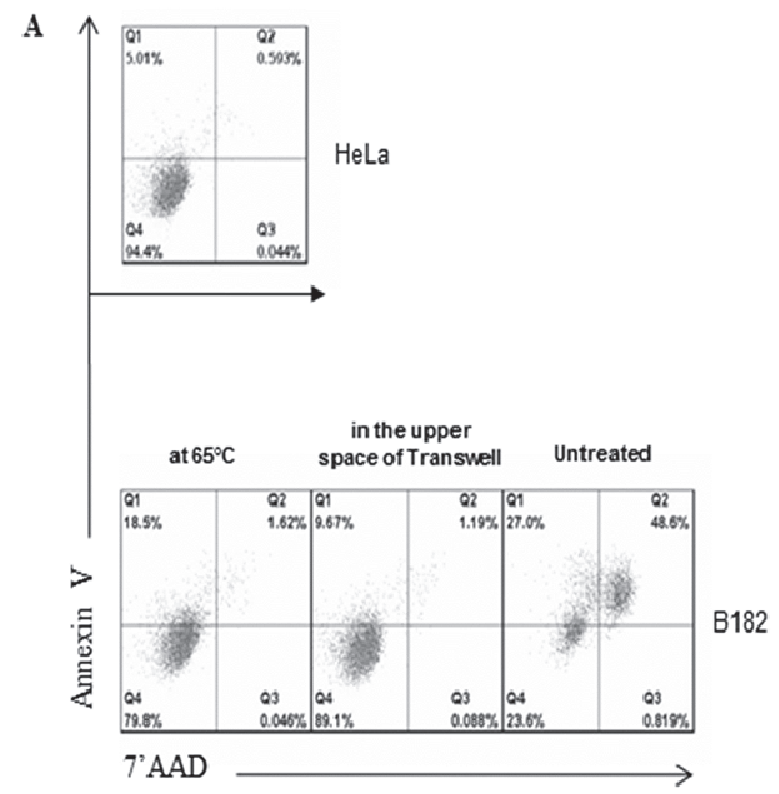

B
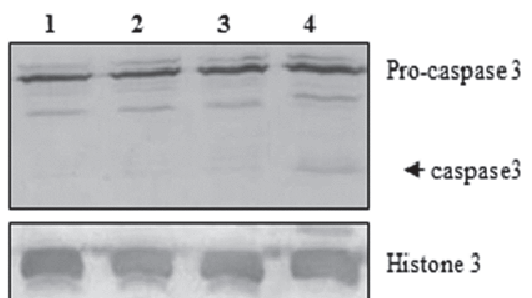

C

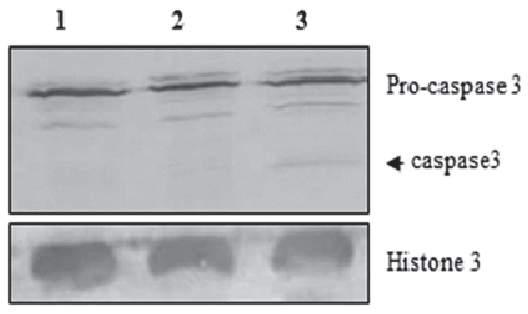

Fig. 5

figure 5 Le Gall et al . 
A

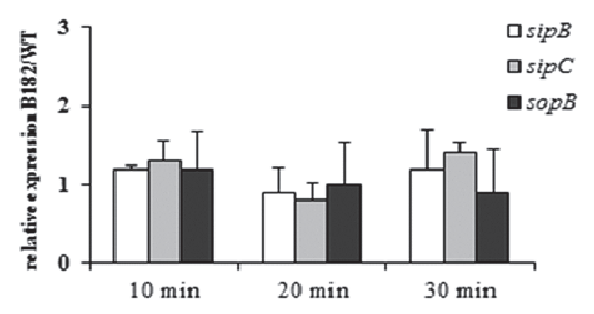

B

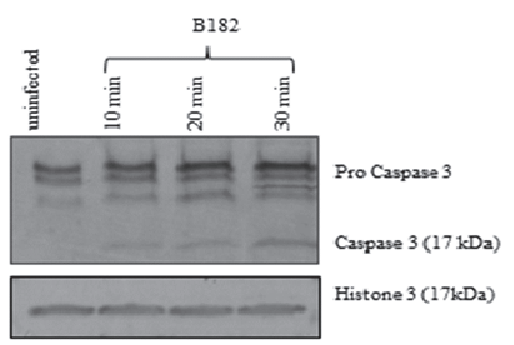

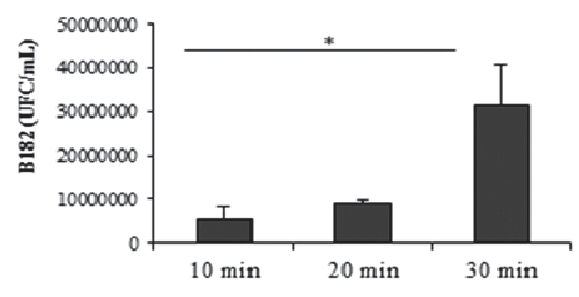

D

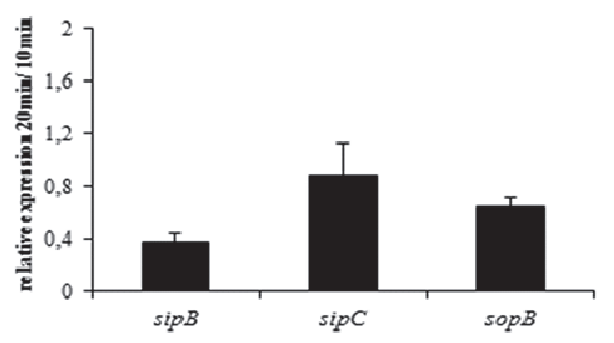

Fig. 6

figure $6 \mathrm{Le}$ Gall et al . 


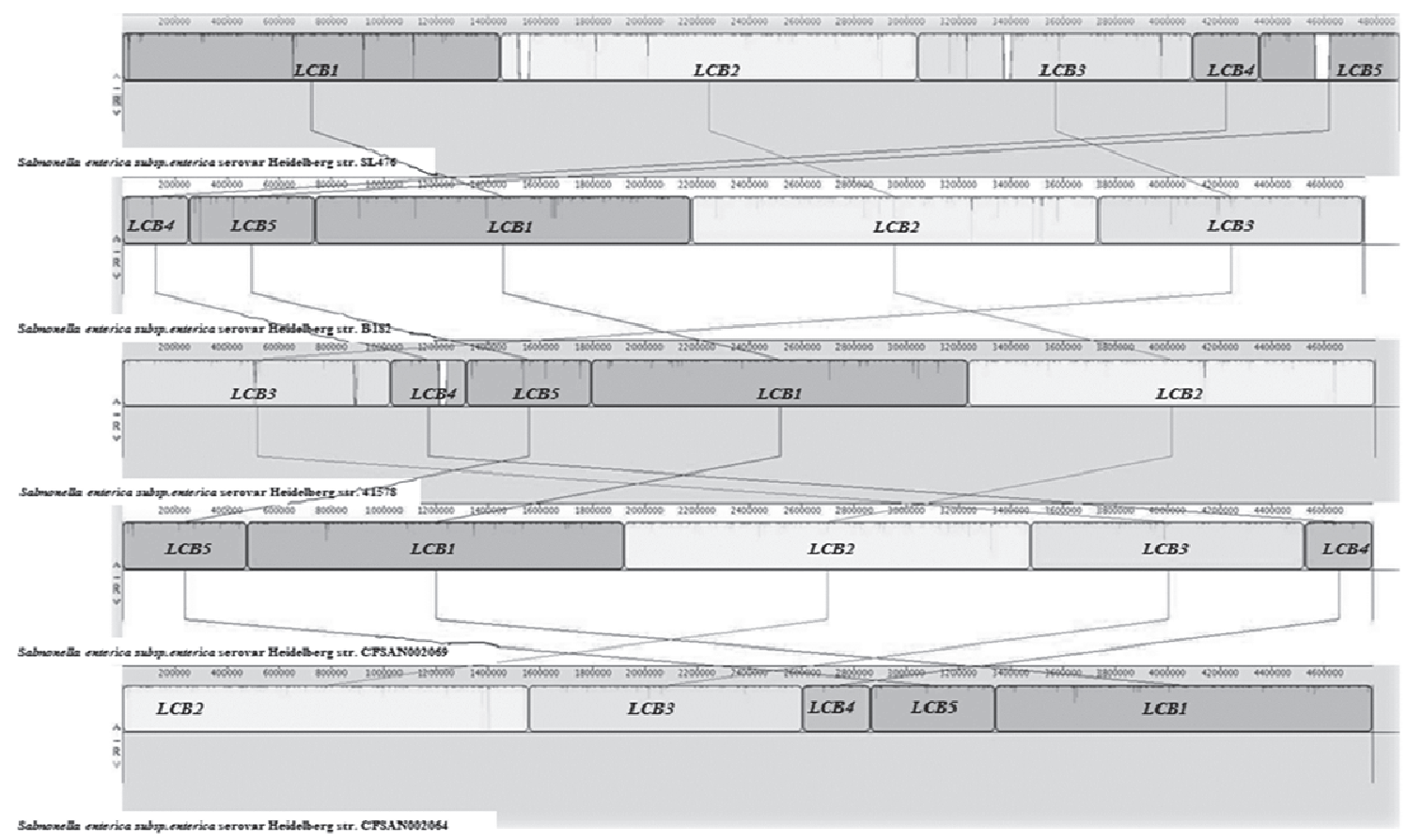

Fig. 7

figure 7 Le Gall et al . 


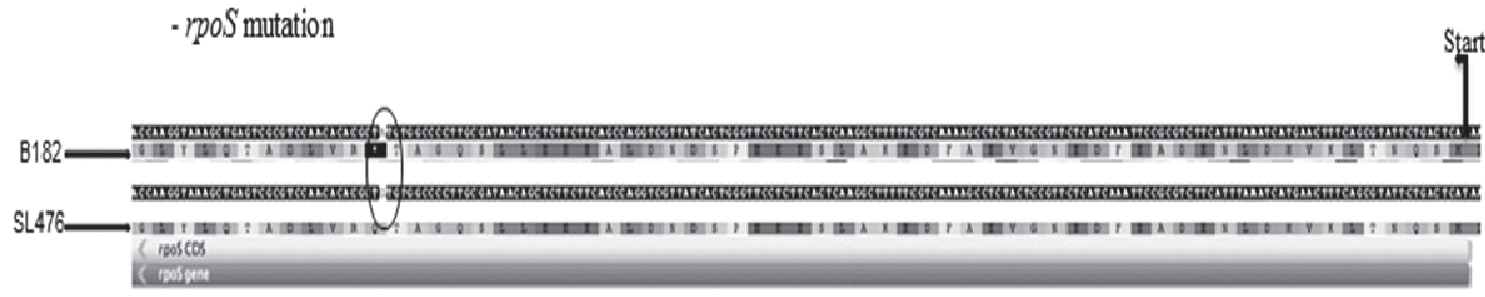

- Irp mutation

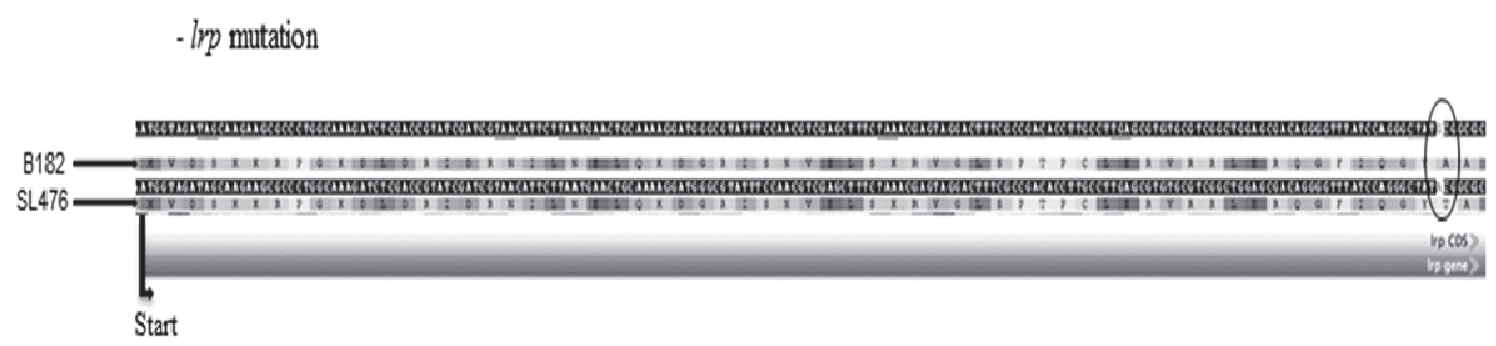

Fig. 8

figure 8 Le Gall et al . 